\title{
Uma Competência Emergente na Gestão Escolar: A Animação Cultural
}

\author{
Vera Vergara Esteves \\ Wally Chan Pereira \\ Lucia Maria França Siano
}

\section{RESUMO}

conceito de gestão está relacionado ao conhecimento e à prática que fazem as organizações funcionarem em relação a determinados objetivos.A escola é o espaço público escolhido pela sociedade para, através de suas ações, atingir seus objetivos educacionais. Nas escolas inseridas ou junto a comunidades carentes, surge no Brasil, nos anos 80, a figura do animador cultural, que passa a realizar um trabalho de educação popular, mais relacionado, em geral às artes e educação física, por serem, em geral, profissionais dessas áreas. Enquanto em nosso país não há uma formação específica, na Franca, o animador cultural possui formação em curso em nível universitário, chegando a atingir um contingente de cerca de 200.000 profissionais. Propomos nesse trabalho a mudança de eixo da animação cultural em escolas brasileiras, ou seja, que ela se fundamente em uma posição que ultrapasse a de educação popular dos anos 80 para um conceito habermasiano de desenvolvimento da subjetividade para atingir a autonomia do sujeito, conjugado a uma ação comunicativa nas comunidades próximas e envolvido com um projeto de profissionalização baseado em competências. Palavras-chave: Gestão. Animação cultural. Profissionalização. Competências.

\section{ABSTRACT}

Professora do Curso de Mestrado da Faculdade de Administração e Ciências Contábeis da UFRJ meyleng@uol.com.br Lucia Maria França Siano Mestre em Educação, PUC/RJ Professora Aposentada da Faculdade de Educação da UFRJ Assessora Pedagógica da Universidade Castelo Branco -UCB lsiano@globo.com
An emerging competency in school administration: cultural

\section{animation}

The concept of administration is related to knowledge and practice, which lead the organizations to perform in terms of set objectives. School is the open space cho- 
sen by society to, through its actions, reach educational targets. The figure of cultural animator arises in Brazil in the 80's at schools inside or next to needy communities, and who starts to carry out a popular education process in general more connected to arts and physical fitness, as they are, in general, professionals in these areas. Whereas in Brazil there is no specific formation for this professional, in France the cultural animator has a university degree, encompassing a range of about 200.000 professionals. We propose in this work a change in direction of cultural animation in Brazilian schools, that is, it should be based on a position transcending popular education of the 80's to a "habermasian" concept of subjectivity development to enable individual autonomy, simultaneous to a communication action in near communities and involved with a project of professionalisation based on competencies.

Keywords: Administration. Cultural animation. Professionalisation. Competencies.

\section{RESUMEN}

\section{Una competencia emergente en la gestión escolar: animación cultural}

El concepto de gestión está relacionado al conocimiento y a la práctica que hacen con que las organizaciones actuen a propósito de determinados objetivos.La escuela es el espacio público elegido por la sociedad para, mediante sus acciones, alcanzar sus objetivos educacionales. En las escuelas insertas o junto a comunidades necesitadas, surge en Brasil, en los años 80, la figura del animador cultural, que pasa a efectuar un trabajo de educación popu- lar, más relacionado, en general, a las artes y a la educación física, ya que son, en general, profesionales de esos campos de actividad. Mientras en nuestro país no hay una formación específica, en Francia, el animador cultural tiene formación en curso a nivel universitario, llegando a un contingente de cerca de 200.000 profesionales. Proponemos en este trabajo el cambio del eje de la animación cultural en las escuelas brasileñas, o sea, que ella se fundamente en una posición que sobrepase la de la educación popular de los años 80 para un concepto habermasiano de desarrollo de la subjetividad para alcanzar la autonomía del sujeto, conjugado a una acción comunicativa en las comunidades prójimas e involucrado con un proyecto de profesionalización fundamentado en competencias.

Palabras clave: Gestión. Animación cultural. Profesionalización. Competencias.

É no cotidiano que se constrói a cultura e a história de uma sociedade. As instituições criadas para sustentar a sua manutenção são, ao mesmo tempo, responsáveis pelas transformações que ocorrem nessa sociedade, uma vez que suas normas obedecem a diretrizes políticas que se constroem historicamente.

O conceito de cultura pode ser examinado por diversas visões teóricas; como; a) sistema de significação (GEERTZ, 1978); b) expressão política da inserção social dos diferentes grupos que compõem a sociedade (MORIN, 1979); c) sistema de comparação entre cultura e distância social. (BOURDIEU, 1979).

Segundo Geertz (1978) o homem vê o mundo através de sua cultura e pode leválo a considerar o seu modo de vida como o mais correto e mais natural. 
O conceito de cultura é essencialmente semiótico. Acreditando como Max Weber, que o homem é um animal amarrado a teias de significado que ele mesmo teceu, assumo a cultura como sendo essas teias e sua análise; portanto, não como uma ciência experimental em busca de leis, mas como uma ciência interpretativa, à procura do significado. (GEERTZ, 1978, p. 15).

Segundo o autor essa interpretação se concretiza numa descrição densa, feita pela etnografia que é uma hierarquia estratificada de estruturas significantes. Para se conhecer as dimensões significantes dessas estruturas é necessário que se mergulhe no meio delas; "não são as nossas questões as mais profundas, mas as respostas que outros deram".

A cultura encarnada e socializada tem um papel cada vez mais central a desempenhar na construção de um futuro para as nações pobres.

No Brasil, a produção cultural, não depende apenas de tecnologias sofisticadas, pode ser criada por uma população muitas vezes iletrada, sem necessidade de técnicas científicas, mais próxima ao senso comum, com grande riqueza de inventividade.

Segundo Bosi (1992, p. 309)

[...] poderíamos falar em uma cultura erudita brasileira, centralizada no sistema educacional (e principalmente nas universidades), e uma cultura popular, basicamente iletrada, que corresponde aos mores materiais e simbólicos do homem rústico, sertanejo ou interiorano, e do homem pobre suburbano ainda não de todo assimilado pelas estruturas simbólicas da cidade moderna.
A cultura está, também, estreitamente relacionada às respostas dadas aos grandes desafios contemporâneos, como a aceleração da construção européia, a mundialização, a sociedade da informação, o emprego e a coesão social.

Encontramos três conjuntos culturais bem diferenciados: a cultura erudita (concentrada nas universidades), a indústria cultural e a cultura popular.

A evolução tecnológica, produzida por uma cultura erudita se desenvolve pela pesquisa científica universitária e se transmite a partir de um processo de escolarização às demais gerações e membros da sociedade.

A cultura de massa, ou indústria cultural, atinge todos os estratos da sociedade, crescendo mais significativamente no interior das classes médias.

A cultura popular pertence, tradicionalmente, aos estratos mais pobres, o que não impede o seu aproveitamento pela cultura de massa e pela cultura erudita,

Recentemente, Yúdice (2005) analisa, a partir de suas pesquisas no continente americano, dos Estados Unidos ao Brasil, como a cultura tem sido tratada e assimilada nos últimos anos em fóruns internacionais, sendo objeto de negociações em tratados de livre-comércio e de políticas de inclusão social.

Yúdice (2005) defende a idéia de que a cultura, cada vez mais, a partir, principalmente, dos últimos vinte anos, deve ser percebida e valorizada da mesma forma que os recursos naturais: assim como a água ou as florestas. Com as novas tecnologias 
da informação e da comunicação o capital mais importante é o capital do conhecimento: as idéias, a informação. Para ele, é a desmaterialização dos recursos.

A cultura, em sua opinião, deve ser gerenciada, a fim de garantir o equilíbrio de interesses entre os formadores, criadores, empresas e sociedade, ou seja, como recurso para fortalecer o tecido social. Não se pode pensar em cultura, sem pensar em economia e bem-estar social. Isso não significa que essa responsabilidade esteja somente nas mãos do governo, mas nas articulações entre instituições do governo e organizações da sociedade civil, entre elas, a escola.

A escola tanto como organização ou instituição da sociedade surgiu na sociedade pela necessidade de conservação e de desenvolvimento cultural. A ação transformadora do processo educativo ocorre, segundo Saviani (1991), quando se pretende que o saber espontâneo, natural seja superado pelo saber metódico e sistemático da cultura erudita. Tal superação se dá, quando o saber objetivo da ciência se converte em saber escolar, não apenas em nível de assimilação, mas quando o sujeito consegue ele próprio apreender a construir e produzir seu conhecimento.

É através da direção tomada pelo processo educativo na escola que poderemos considerá-la como instituição capaz de transmitir, através da sua práxis, tanto os conhecimentos e os valores considerados válidos, como o processo de construção e produção cultural. Para tanto é necessário identificar as condições que viabilizam o alcance desse objetivo na instituição escolar.
Quem orienta a direção do processo educativo na escola?

Krawczyk (1999) refere-se à gestão da escola, relacionando-a às relações de poder no interior do sistema educativo e da instituição escolar, assim como ao caráter regulador do Estado e da sociedade no âmbito educacional. Destaca o papel articulador da gestão entre metas, definições políticas e as práticas escolares, ou seja, define gestão como um espaço de "encontro entre o Estado e a sociedade civil na escola". Logo, a gestão escolar não se esgota no âmbito da escola, mas encontrase inserida na gestão do sistema educativo, incluindo o espaço sociocultural. Ou seja, a gestão da escola deve ter a preocupação em construir uma identidade institucional, comunitária e cultural.

\section{Mudanças na Gestão Escolar}

A influência dos pressupostos das teorias clássicas, enfatizando a eficiência econômica e a racionalidade técnica do modelo burocrático, retiraram da administração escolar a ênfase nas atividades-fim, isto é, no que se refere à educação propriamente dita, dando relevo especial às atividadesmeio, restringindo-se, quase sempre, à qualidade formal do processo pedagógico.

Nos anos 60 e 70 a administração escolar funcionou com ênfase na divisão social do trabalho - administração, supervisão escolar e orientação educacional, exercendo um poder coercitivo sobre o corpo docente e discente.

Nos anos 80, inicia-se na escola uma nova estratégia, em nível sociocultural, su- 
blinhando a participação da comunidade. É um novo paradigma organizacional que se propõe a mobilizar a comunidade interna e externa próximas, através de mais informação, mais inclusão social e cultural, compromisso coletivo, delegação de responsabilidade e descentralização nas decisões, em contraposição aos modelos de centralização técnico-burocrática e cultura erudita da década anterior.

A expressão gestão escolar cunha-se, nesse momento, para designar a ampliação dos conteúdos da área de administração, abrangendo, além da organização do trabalho escolar, a área pedagógica e a democratização do papel do gestor, que se estende para toda a comunidade.

Esse conceito de gestão escolar começa a ser experimentado por algumas instituições, a partir da democratização da sociedade brasileira, principalmente ao final da década de 80, quando se constatou uma mudança da unipessoalidade da autoridade do diretor da escola e da linha hierárquica vertical, com nítida separação entre a concepção e a execução das atividades administrativas e educacionais, para o início de direção colegiada compartilhada.

É através dos valores que orientam as ações da escola que poderemos chegar a construir uma ética profissional capaz de aceitar a pluralidade sem, no entanto, haver uma ruptura em nível de objetivos. É, portanto, tarefa da gestão, através da ação administrativa participativa, buscar através dessa ação, o estabelecimento dos princípios básicos e dos valores que irão subsidiar a práxis escolar, propiciando o surgimento de uma filosofia e uma cultura organizacional que acolha tanto as diferenças comuni- tárias como individuais, na construção do projeto pedagógico da escola.

$\mathrm{Na}$ educação institucionalizada, é necessária uma cultura organizacional que leve em consideração a transformação de valores, costumes e crenças sociais no universo sociocultural da realidade escolar, deixando de considerar, como diz Geertz (1978) o seu modus faciendi como o mais correto e mais natural, acolhendo as mudanças da realidade escolar, na medida em que esse acolhimento busque atingir um agir comunicativo entre escola - comunidade.

\section{A Organização Escolar e seu Contexto}

No âmbito em que a escola está situada, Erny (1981, grifo do autor) mostra que, aos fatores que dependem do contexto social, é preciso acrescentar aqueles que se prendem mais diretamente à ordem da cultura e se relacionam às maneiras de viver e de pensar, em outras palavras, à história e aos conteúdos da vida social próprios a cada população e que se apresentam, igualmente, como objetos de aprendizagem.

Deve-se pensar, segundo Erny (1981, p. 126), pragmaticamente nos seguintes pontos:

- suas bases geográficas, ecológicas, econômicas e demográficas;

- sua tecnologia (ferramental, habitação, alimentação, vestimenta, técnicas corporais );

- seus sistemas de comunicação: língua, mímicas, gestos, outros sistemas de signos convencionais, tais como os semáforos e os sinais de trânsito;

- as estruturas sociais e os sistemas de qualificação e de atitudes que delas derivam; 
- seus sistemas de representações;

- seus sistemas de valores;

- seu ethos, sua sensibilidade, sua maneira particular de sentir as coisas e reagir afetivamente;

- seu patrimônio, o que ela transmite de geração a geração sob forma de um saber codificado, de produções artísticas, de construções, de meios de comunicação, de literatura;

- seu estilo de pensamento, de vida, de relação, de expressão;

- a dinâmica que a anima.

Como podemos inferir, a gestão escolar não é tarefa que se realiza apenas no âmbito restrito da organização escolar, no que ela tem de particular, mas exige conhecimento e diálogo com a comunidade, em função de uma estratégia que se concretiza no projeto do estabelecimento, expressão de uma proposta coletiva, permanentemente (re)elaborado pela comunidade escolar. Sua utilização permite a criação de processos instituintes e endógenos, de produção de inovações nas escolas, que se contrapõem às estratégias puramente burocráticas e administrativas, a partir de diretrizes traçadas pelo sistema escolar central, que, praticamente, não reconhecem a autonomia e a individualidade da escola e do contexto sociocultural em que se situam.

Compreendendo a escola como instituição marcada por sua natureza educativa, como espaço auto-organizado de conservação e de transformação cultural, observamos que muitas das competências administrativas tradicionais, como o planejamento, a organização, a coordenação e a avaliação, permanecerão, por força das necessidades ad- ministrativas e pedagógicas, como projeto concebido a partir de seu interior e a gestão escolar como a ponte entre o político, o administrativo e o pedagógico, emergem novas competências cognitivas, comunicativas e socioculturais, como a própria gestão, a informática e a animação cultural.

Por esse novo paradigma, a gestão escolar busca a auto-regulamentação e a autonomia dos atores sociais, pelo exercício da participação, aliada ao profundo conhecimento de sua missão e de sua cultura.

Por intermédio da Escola. no Brasil, com apoio governamental e não-governamental, das ONGs e das associações comunitárias, tem ocorrido mudança de valores e de hábitos sociais como o cuidado com a preservação de florestas, a diminuição da pesca predatória e do trabalho infantil, entre outros.

Nessas comunidades tem havido um trabalho constante, persistente que exigiu um projeto pedagógico com grande conhecimento da comunidade, suas associações e líderes locais. É um processo longo, muitas vezes lento de negociação entre a Escola, o Estado e a Comunidade para obter a concretização de um processo coletivo, que geralmente é reformulado, lentamente, por problemas que vão surgindo no cotidiano.

Esse processo é, às vezes, mais facilmente desenvolvido em comunidades menores; ao passo que, no complexo urbano, a mudança de valores e de hábitos sociais é um processo mais difícil, pois a escola sofre influências tanto da mídia, como de segmentos sociais marginais que pressionam e, às vezes, condicionam tanto o comportamento das famílias como dos alunos. 
Esses projetos influenciam na Escola os currículos, as atividades multiculturais dos conteúdos programáticos, de acordo com a realidade próxima, assim como, esta é influenciada pela educação de base adquirida na escola e levada, pelos alunos, às suas famílias.

Diante do exposto, julga-se que a animação cultural poderá se constituir em valioso instrumento para a escola. No entanto, no Brasil, para se implantar a animação cultural, a sociedade necessita identificá-la como uma transformação política e social com objetivos bem definidos, para realizar como um dos produtos culturais a autonomia do sujeito, através da sua qualificação profissional.

No Brasil, essa temática ainda não tem merecido por parte dos pesquisadores um tratamento especial, como ocorre em outros países, como a França, onde já se criaram cursos superiores específicos nessa área de conhecimento.

Neste trabalho vamos focalizar a animação cultural, como produto da gestão escolar.

\section{Teoria da}

\section{Animação Cultural}

A animação cultural tem sido praticada como um campo de luta pela afirmação da cidadania, como valorização do social e do fortalecimento da democracia, na qual a participação é obrigatória.

Pretende atingir o mundo objetivo de quem fala - o mundo social - e o mundo próprio, subjetivo do sujeito. Por intermédio do diálogo e da ação comunicativa, possibilita que o sujeito analise, no seu contexto, suas experiências em relação à sua circunstância e ao outro, viabilizando ainda a tomada de consciência de seu destino histórico e o (res)surgimento da solidariedade pelo engajamento coletivo.

A linguagem da Animação Cultural deve preencher as três funções da comunicação citadas por Habermas (1989): a reprodução cultural, a integração social e a socialização da interpretação cultural das necessidades. Logo, a animação tem uma ação educativa face uma sociedade minada por privilégios e pela manipulação; tenta desenvolver o diálogo, a ação comunicativa e a solidariedade. É um método dialético de transformação social.

A animação cultural poderá participar da fundação de novos modos de pensamento, novas racionalizações, novas perspectivas de utopia e de contribuição para a renovação de princípios organizacionais das sociedades. A animação existe como uma práxis, uma interação da reflexão e da prática.

Observa-se uma evolução no conceito de animação. Conforme Gillet, (2003, p. 1)

a primeira fase, de caráter ideológi-

co, caracteriza a animação como uma ação pedagógica para o indivíduo tomar consciência da liberdade a ser conquistada. Tal concepção apresenta três orientações essenciais:

a) próxima à tradição da educação popular, é herdeira do iluminismo e das idéias republicanas. Visa desenvolver cidadãos esclarecidos pela posse de grandes linguagens racionais, estéticas e econômicas para 
participarem da vida democrática e das transformações necessárias;

b) segue a linha de Durkheim e tem como função desbloquear as comunicações sociais e desenvolver a adaptação às novas formas de vida. Foi uma orientação predominante nos anos 50 e 60, nas ações comunitárias dos bairros;

c)e a visão próxima do marxismo tem a perspectiva de alargamento da consciência política visando à liberdade total.

O campo da animação é o da ciência na prática, tendo seguido dois modelos básicos:

1. consumista - É a animação reduzida a seu valor de uso; o modelo privilegia a ação, o agente, o programa, o instituído, a socialização, o consumo e a prática. $\bigcirc$ papel é passivo: pessoas e grupos sociais têm produtos para consumir.

2. animação abstrata - tem, sobretudo valor de troca. É lugar de criação, transformação de valores simbólicos, um vetor abstrato em torno de questões que afetam toda a sociedade. $\bigcirc$ modelo privilegia a ação, o ator, o projeto, o instituínte, a sociabilidade, o conflito, a práxis.

Pelo exame das categorias dos dois modelos, no quadro abaixo, podemos situálos, o primeiro na sociologia do consenso e o segundo na sociologia do conflito. Nesta a lógica do ator se coloca como prioritária à lógica do sistema para analisar o contexto social, através da autonomia do sujeito e de uma ação comunicativa nas comunidades, envolvendo um projeto que encontra, na animação cultural, o eixo condutor da transformação sociocultural.

\begin{tabular}{|c|c|}
\hline \multicolumn{2}{|c|}{ Categorias Básicas da Animação Cultural } \\
\hline Modelo Consumista & Modelo de animação abstrata \\
\hline Ação & Ação \\
\hline Agente & Ator \\
\hline Programa & Projeto \\
\hline Instituído & Instituínte \\
\hline Socialização & Sociabilidade \\
\hline Consumo & Conflito \\
\hline Prática & Práxis \\
\hline
\end{tabular}

\section{Animação Cultural}

\section{e seus Atores}

No Brasil, nos anos 80, nas escolas junto a comunidades carentes, surge a figura do animador cultural, que passa a realizar um trabalho de educação popular, mais relacionado, às artes e educação física, por serem, em geral, profissionais dessas áreas.

As crises sociais mobilizaram o pensamento sociológico e psicológico em direção a uma práxis, sendo construídos três paradigmas de animação cultural que visavam:

1) à articulação de uma teoria da animação com uma teoria dos atores-anima- 
dores, mobilizados pela paixão e curiosidade, permeadas pela dúvida para minimizar a subjetividade;

2) a lógica do ator prioritária à lógica do sistema para analisar o contexto social;

3) o apoio da psicologia e da sociologia ao estudo do animador e de seu ambiente sociocultural.

Atualmente, nos países europeus, os atores da animação cultural estão vivenciando uma fase onde dispõem de mais de um modelo de intervenção na sua bagagem profissional, que lhes permitem negociar o tempo e o espaço de cada uma de suas estratégias, o que supõe uma nova estruturação, uma recomposição do campo de atuação.

A ação desses atores exige um trabalho dotado de um sistema de representações sobre seu valor social, seu saber sobre as relações sociais que sustentam em um projeto educacional. Sua concepção de trabalho, uma prática profissional de intervenção com estratégias autônomas, levando em conta a realidade social, econômica e cultural, o papel do Estado e de outros atores comunitários, sem perder de vista o plano político, os ideais e os valores fundamentais da animação.

As competências do animador cultural poderão, assim, evoluir, utilizando as idéias de desenvolvimento da subjetividade de Habermas (1989) - a ação comunicativa - para atingir a autonomia do sujeito, garantir a inclusão buscada pelos grupos da população desejosos de terem consciência do que ocorre em seus territórios para fazer valer seus direitos.

objetivo da animação consiste em criar as condições máximas para que o sujeito se torne o que ele é, isto é, abandonar as imagens de excluído como portador de conhecimentos de base, com possibilidades intelectuais limitadas e mesmo de caráter instável e substituí-las por um postulado de potencialidade do sujeito. Visa colocar todos os cidadãos em posição de gerar seus próprios negócios, de participar da cooperação social com base no respeito às condições de igualdade e inserido, portanto, em uma concepção humanista da animação cultural.

Logo, os atores da animação cultural são todos os membros da comunidade educativa, quando visam à transformação, quando participam da elaboração de regras de ação democrática, quando atuam, na comunidade, contra a exclusão, as interdições, as turbulências e desordens que contribuem para minimizar o bem estar da comunidade.

\section{O Locus da Animação Cultural e as Competências do Gestor Escolar}

A animação cultural exerce, além das funções de socialização e de inovação, funções lúdicas, criativas, educativas e culturais. Essas funções são também ações próprias à organização escolar; o que leva a considerá-la como espaço de animação cultural e, por isso, o gestor como um de seus atores.

A gestão escolar estaria localizada no modelo de animação abstrata por seu caráter pró-ativo, marcado por uma práxis de transformação, em que a ação dos atores está intimamente relacionada ao projeto pedagógico da escola, que não pode ignorar na sua implementação o conflito que pode surgir no embate das opiniões da comunidade, apesar da sociabilidade latente que direciona a ação de seus integrantes, em função dos objetivos comuns de educação, que são perseguidos pela organização escolar. 
Por exemplo, numa comunidade em que o palmito é praticamente a principal fonte de alimentação, em que os grupos sociais fazem uma utilização predatória dessa fonte nutricional com perigo de extinção da mesma, é função da escola, por intermédio do seu projeto pedagógico, oferecer orientação, com risco inicial, até de conflitos com alguns predadores, para que haja modificação de hábitos, replantando, preservando e respeitando os ciclos de vida da natureza; assim como a formação de profissionais para exercerem atividades que contribuam para o do equilíbrio ecológico na região.

Já, uma orientação com maior nível de complexidade, é aquela referente às relações da escola e comunidade com vistas à condenação de articulações com o narcotráfico, uma vez que, o desemprego, em grupos em que os valores básicos de cidadania são tênues, às vezes, justifica qualquer ganho para satisfazer necessidades básicas. Nesse caso, o trabalho da escola e da animação cultural tem que se realizar em um sentido preventivo de educação, incluindo a qualificação, e fortalecimento das manifestações culturais da comunidade, junto às crianças e aos adolescentes, para evitar, mais tarde, sua cooptação, por falta de opção de vida.

gestor educacional, na implementação dessa práxis transformadora, necessita agir como ser competente na área das relações políticas, técnicas e humanas. Como gestor-ator cultural, desenvolve uma ação política com a comunidade escolar, em função dos objetivos do projeto pedagógico de sua escola; necessitando também ser um técnico em sua área de atuação - a educação - para que, como o gestor-ator da animação cultural, consiga realizar, no âmbito das relações humanas, um processo de comunicação que possibilite a intervenção necessária de estímulo à afirmação da identidade cultural e conseqüente desenvolvimento do Eu social, por intermédio da ação comunicativa, através do diálogo, buscando, entre os sujeitos, formas recíprocas cada vez mais altas de reflexão, que contribua para o aperfeiçoamento da conscientização.

A ação política, a competência técnica e a de comunicação são categorias comuns às duas competências do gestor escolar - a educacional e a da animação cultural, que se fundem na sua atuação como ator mediador e integrador, no âmbito da sua instituição.

Para que a função de socialização da animação cultural seja desenvolvida, o gestor educacional precisa conhecer o contexto sociocultural de sua instituição, isto é, das bases histórico-geográficas, ecológicas, econômicas e demográficas, no sentido de tornarem conhecidas tanto suas problemáticas quanto para minimizá-las e utilizar seu potencial, através de práticas inovadoras, em benefício da comunidade.

Para que a função lúdica da animação cultural se desenvolva, é necessário que o gestor efetive uma comunicação com a população alvo que deve ser empreendida por meio de um sistema que pressupõe competente domínio da linguagem e todos os outros sistemas de manifestações culturais, visuais e simbólicas em uso na região.

No que diz respeito à função criativa, o gestor educacional deve conhecer profundamente os sistemas de representação da comunidade para, a partir deles, fomentar a inovação na comunidade, a fim de que 
as peculiaridades locais sejam ressaltadas e valorizadas, talvez até, além de fronteiras nacionais, tornando-se além de capital cultural, capital financeiro.

É através da competência inovadora da animação cultural que se dará o alargamento da consciência política, pelo conhecimento real das estruturas sociais e dos sistemas de qualificação e de atitudes que delas derivam, no sentido de começar a empreender as mudanças que se mostrarem necessárias.

Nas grandes cidades, o gestor educacional precisa ser competente no sentido de incentivar, em toda equipe, o conhecimento das circunstâncias inerentes ao contexto sociocultural em que a comunidade está situada e as influências exercidas pelos processos desenvolvidos pelas agências encarregadas de difundirem os valores relativos à mundialização da cultura.

A mudança de eixo da animação cultural se fundamenta em uma posição que ultrapasse aquela já descrita nos anos 80, (apenas voltada para a educação popular relacionada às artes e educação física), para um conceito habermasiano mais amplo de desenvolvimento da subjetividade para atingir a autonomia do sujeito, conjugado a uma ação comunicativa conscientizadora nas comunidades, acerca das necessidades de religação e de solidariedade, integrado a um projeto de formação do gestor escolar, baseado em competências tradicionais e emergentes.

\section{Referências}

BOURDIEU, P. La distinction: critique sociale du jugement. Paris: Les Editions de Minuit, 1979.

CANÁRIO, R. Estabelecimento de ensino: a inovação e a gestão de recursos humanos. In: NÓVOA, A. As organizações escolares em análise. Lisboa: Dom Quixote, 1995.

DEROUET, J. L. Une sociologie des étabilissement scolaires: les difficultés de construction d'um nouvel objet scientifique. Revue Française de Pédagogie, Paris,

n. 78, p. 73-108, 1987.

ERNY, P. Etnologia da educação. Rio de Janeiro: Zahar, 1981.

GEERTZ, C. A interpretação das culturas. Rio de Janeiro: Zahar, 1978.

GILLET, J. C. Anotações sobre a Teoria da Animação. Disponível em:

$<$ http:www.colloquecs-isiat.fr.st $>$. Acesso em: 7 maio 2003.

HABERMAS, J. Consciência moral e agir comunicativo. Rio de Janeiro: Tempo Brasileiro 1989. 
KRAWCZYK, N. A gestão escolar: um campo minado: análise das propostas de 11 municípios brasileiros. Educação \& Sociedade, Campinas, SP, v. 20, n. 67, p. 112-149, ago. 1999.

MORIN, E.O enigma do homem: para uma nova antropologia. Tradução de Fernando de Castro Ferro. Rio de Janeiro: Zahar, 1979.

SANTOS, B. S. (Org.). Produzir para viver: os caminhos da produção não capitalista. Rio de Janeiro: Civilização Brasileira, 2002.

SAVIANI, D. Pedagogia histórico-crítica: primeiras aproximações. São Paulo: Cortez: Autores Associados, 1991. (Coleção polêmicas do nosso tempo; v. 40).

YÚDICE, G. A conveniência da cultura: usos na era global. Tradução de Marie-Anne Kremer. Belo Horizonte: Editora UFMG, 2005.

Recebido em: 17/09/2004

Aceito para publicação em: 08/11/2004 